\title{
Dietary Eucommia ulmoides Extract Alleviates the Effect of Cold Stress on Chick Growth Performance, Antioxidant and Immune Ability
}

\author{
Ting $\mathrm{Hu}{ }^{1,2,3}$, Yue Lei ${ }^{1,2,4}$, Minxue Li ${ }^{1,2}$, Qin Liu ${ }^{5}$, Li Song ${ }^{1,2, *}$ and Degang Zhao ${ }^{1,2,6, *}$ \\ 1 Key Laboratory of Plant Resource Conservation and Germplasm Innovation in Mountainous \\ Region (Ministry of Education), Guizhou University, Guiyang 550025, China; hut1020@163.com (T.H.); \\ leiyue94@163.com (Y.L.); lmxzm95@163.com (M.L.) \\ 2 Guizhou Key Lab of Agro-Bioengineering, Institute of Agro-Bioengineering, Guizhou University, \\ Guiyang 550025, China \\ 3 College of Life Sciences, Guizhou University, Guiyang 550025, China \\ 4 Guizhou Institute of Subtropical Crops, Xingyi 562400, China \\ 5 College of Animal Science, Guizhou University, Guiyang 550025, China; lpslq95@gmail.com \\ 6 Guizhou Academy of Agricultural Science, Guiyang 550006, China \\ * Correspondence: lpsssl@126.com (L.S.); dgzhao@gzu.edu.cn (D.Z.)
}

\section{check for} updates

Citation: Hu, T.; Lei, Y.; Li, M.; Liu, Q.; Song, L.; Zhao, D. Dietary Eucommia ulmoides Extract Alleviates the Effect of Cold Stress on Chick Growth Performance, Antioxidant and Immune Ability. Animals 2021, 11, 3008. https://doi.org/10.3390/ ani11113008

Academic Editors: Marta I. Miranda Castañón, Einar Vargas-Bello Perez and Manuel Gonzalez

Received: 7 September 2021

Accepted: 16 October 2021

Published: 20 October 2021

Publisher's Note: MDPI stays neutral with regard to jurisdictional claims in published maps and institutional affiliations.

Copyright: (c) 2021 by the authors Licensee MDPI, Basel, Switzerland. This article is an open access article distributed under the terms and conditions of the Creative Commons Attribution (CC BY) license (https:// creativecommons.org/licenses/by/ $4.0 /)$.
Simple Summary: The cold stress that chicks suffer from has caused huge losses to the chicken industry. It is very important to find an effective way to alleviate cold stress in chicks. This study was designed to test the hypothesis that dietary Eucommia ulmoides extract alleviates the effect of cold stress on chick growth performance, antioxidants, and immune ability. Interestingly, Eucommia ulmoides extract supplementation improved the growth performance, antioxidant status, and immune response and reduced the organ damage of chicks caused by cold stress, which shows that Eucommia ulmoides extract has potent protective effects against cold stress. These findings will be very beneficial to break down the bottleneck issue of chick production caused by cold stress.

Abstract: This study aimed to investigate the protective value of Eucommia ulmoides extract (EUE) on chicks under cold stress. A total of 21 compounds were identified in EUE using mass spectrometry (LC-MS). Ninety chicks were divided into a control group (CS) fed a basal diet and an experimental group supplemented with EUE, exposed to $10 \pm 1{ }^{\circ} \mathrm{C}$ for $8 \mathrm{~h}$ per day. Results showed, compared with the CS group, the body weights (BW) $(p<0.01)$ and average daily gains ADG $(p<0.05)$ of the EUE group were increased throughout the study period. Chicks fed EUE had higher AFI $(0-7 d, p<0.001)$ and lower feed-to-gain ratios $(\mathrm{F} / \mathrm{G})(0-15 \mathrm{~d}, p<0.001)$. EUE increased the activities of superoxide dismutase (SOD) (15 d, $p<0.05)$ and glutathione peroxidase (GSH-Px) $(7 \mathrm{~d}, p<0.05)$, whereas it decreased malondialdehyde (MDA) (15 d, $p<0.01)$. The contents of $\operatorname{Ig} \mathrm{A}(7 \mathrm{~d}, p<0.05), \operatorname{IgG}(7 \mathrm{~d} ; 15 \mathrm{~d}$, $p<0.01)$, and $\operatorname{IgM}(15 \mathrm{~d}, p<0.001)$ were higher in the EUE group. Dietary EUE could also reduce chick organ damage. Overall, EUE as a natural feed additive can improve the growth performance, antioxidant capacity, and immune level, and reduce the organ damage of cold-stressed chicks.

Keywords: Eucommia ulmoides extract; chick; cold stress; growth performance; antioxidant; immune

\section{Introduction}

Temperature is one of the major environmental factors for regulating animal health and survival [1]. It also affects production performance or reduces animal welfare. In critical environmental conditions, the vital physiological processes of homoeothermic animals are usually compromised [1]. Cold stress often occurs in animal management [2]. Low temperature has a negative influence on organisms, including leading to metabolic suppression [3], disrupting hormone release [4], and affecting the activity of protective enzymes [5], which can inhibit growth and increase mortality [2,6]. Low temperature 
also increases the immune-suppression level, free radical load, and leads to oxidative stress [7]. The animal immune system is often vulnerable to low temperatures and through the exacerbation of pathophysiological conditions [8]. Cold stress can also cause damage to the bursa of poultry, heart, intestinal tissue, and other slow development, thus affecting the growth of poultry and even causing death [9-11].

Low temperature is known as a major risk factor for diminishing the growth performance and survival of chicks [12]. Typical features of chicks include short villi, hypoplasia of organs, and an inadequate thermoregulatory system [13]. The hatching and brood temperature of chicks is higher than most other animals such as cattle and sheep. Chicks just out of the shell are highly susceptible to low temperatures, and once the ambient temperature is not sufficient for the chick to grow, this often leads to a high mortality rate [14]. Low temperature also reduces chicken antioxidant capacity [15,16], immune function [17], and damages tissues and organs in chicken [18]. In addition, low temperature can reduce appetite, feed intake, and feed utilization of chicks, which can affect growth performance and product quality [14]. Low temperatures tend to limit poultry production, especially causing serious economic losses to chick production, which is a bottleneck that needs to be solved [15].

Traditional measures to reduce the impact of low-temperature stress on chicks include increasing padding, raising the environmental temperature, adding vitamins and antibiotics, etc., [19-21], which are costly, energy consuming, and environmentally unfriendly [20]. Using medicinal plant additives has been one of the common trends to improve the low-temperature stress on chicks in recent years [22-24]. Feeding Chinese herbal medicines (CHM) can promote animal growth, enhance antioxidant levels, and enhance immune ability $[23,25]$, in order to reduce the impact of environmental stress on the animal.

Eucommia ulmoides is a precious traditional CHM. Its bark, leaves, and flowers have various active ingredients, which can be used as medicine [26]. The medicinal value of Eucommia ulmoides has attracted more and more attention for its chemical composition [27]. Eucommia ulmoides is rich in chemical components, such as iridoids, flavonoids, phenylpropanoids, lignans, and so on $[19,28,29]$. Eucommia ulmoides has a variety of biological activities, including growth promotion [30], metabolic regulation [28], antioxidant abilities [31], immune enhancement [32], anti-inflammatory abilities [28], and other effects. Chlorogenic acid, flavonoid, and rutin in Eucommia ulmoides have an obvious effect of promoting growth [33-35]. Chlorogenic acid, flavonoid, and quercetin have an antioxidant effect [36-39]. Furthermore, flavonoids can improve the immune ability of the body [40]. Studies have reported that Eucommia ulmoides and its extracts can be used as feed additives, which have the functions of improving growth performance, antioxidant capacity, and immune response [41,42]. However, to the best of our knowledge, very few studies have been conducted using Eucommia ulmoides or its extracts for animal cold stress protection. In this study, Eucommia ulmoides leaves (EUL) were used as raw materials to extract the active components and fed to chicks under cold stress, and their growth performance, organ development, serum antioxidant capacity, and immunoglobulin content were determined. The aim of the present study was to explore the effects of EUE on chicks in low-temperature environments, so as to provide a scientific basis for the application of EUE as a feed additive to protect cold-stressed chicks.

\section{Materials and Methods}

All procedures of animal experiments were performed according to the protocol approved by the Guizhou University Subcommittee of Experimental Animal Ethics (EAEGZU-2020-P020, Guizhou, China). The chicks used in this study have been treated humanely. Great efforts have been made to minimize pain. 


\subsection{Preparation of EUE}

EUL was picked from the South Campus of Guizhou University. The Eucommia ulmoides were dried at $80^{\circ} \mathrm{C}$ and crushed by an ultrafine grinder. After being passed through an -80 mesh sieve, the powders were stored at $-20{ }^{\circ} \mathrm{C}$. The powders were supplemented with 10 volumes of distilled water and soaked at room temperature for $2 \mathrm{~h}$ accompanied by stirring several times. Then, the mixtures were extracted in a water bath at $80-90{ }^{\circ} \mathrm{C}$ for $1 \mathrm{~h}$ and centrifuged at $10,000 \mathrm{rpm}$ for $5 \mathrm{~min}$ at $25^{\circ} \mathrm{C}$. The supernatants were dried in an oven at $60{ }^{\circ} \mathrm{C}$ to obtain EUE. Fresh EUL were dried and crushed into EUL powder.

\subsection{Composition Determination of EUL and EUE by LC-MS}

Sample preparations. First, $0.2 \mathrm{~g}$ EUE and EUL powders were respectively placed in $10 \mathrm{~mL}$ centrifugal tubes. The samples were ultrasonically extracted with $50 \mathrm{~mL}$ of $8 \%$ methanol for $40 \mathrm{~min}$ at $45{ }^{\circ} \mathrm{C}$ and left to rest for $5 \mathrm{~min}$. The supernatants were removed, placed in new centrifuge tubes and centrifuged at 13,000 rpm for $10 \mathrm{~min}$, and filtered with a $0.22 \mu \mathrm{m}$ microporous membrane to obtain the extractions, which were stored in a refrigerator at $4{ }^{\circ} \mathrm{C}$.

Chromatographic conditions. Extractions were injected into a C18 column $(100 \mathrm{~mm} \times 2.1 \mathrm{~mm}$, $1.8 \mu \mathrm{m})$ at a $0.3 \mathrm{~mL} / \mathrm{min}$ flow rate. The column temperature was set at $35^{\circ} \mathrm{C}$ and the sample volume was $5 \mu \mathrm{L}$. Gradient elution was performed with mobile phases A $(0.1 \%$ formic acid aqueous solution) and B (acetonitrile) by HPLC (LC-30A, Shimadzu, Kyoto, Japan). The elution procedure was shown in Table 1.

Table 1. The elution program.

\begin{tabular}{ccc}
\hline Time (min) & $\begin{array}{c}\text { A (0.1\% Formic Acid } \\
\text { Aqueous Solution) }\end{array}$ & B (Acetonitrile) \\
\hline 0.010 & 95.0 & 5.00 \\
15.0 & 75.0 & 30.0 \\
30.0 & 5.00 & 95.0 \\
32.0 & 5.00 & 95.0 \\
32.1 & 95.0 & 5.00 \\
35.0 & stop & \\
\hline
\end{tabular}

Mass Spectrometry Conditions. Electrospray ionization was used in the positive ion mode with the following details: Temperature, $600^{\circ} \mathrm{C}$; spray voltage, $5500 \mathrm{~V}$; declustering potential (DP), $100 \mathrm{~V}$; collision energy (CE), $35 \mathrm{eV}$; collision energy spread (CES), $15 \mathrm{eV}$; nebulizing gas, nitrogen; curtain gas, 35 psi; auxiliary gas1, 60 psi; auxiliary gas 2, 50 psi; mass scan, 50 to $1000 \mathrm{~m} / \mathrm{z}$. Electrospray ionization was used in the negative ion mode: Spray voltage, $-4500 \mathrm{~V}$; collision energy $(\mathrm{CE}),-35 \mathrm{eV}$. The rest of the experimental conditions remained in positive ion mode.

\subsection{Animals and Experimental Design}

The animal experiment design was referenced from previous literature [43]. A total of 90 2-week-old healthy chicks (iron-footed hemp variety) with similar BWs were randomly divided into two equal groups ( 45 chicks each group), one of which was randomly selected as the control group and the other as the treatment group. Then, chicks were randomly assigned to 3 stages of the experiment, which were $0 d, 7 d$, and $15 d$, respectively. Each pen had 5 chicks and 3 replicate pens. Chicks in each pen were reared in the same breeding house equipped with a feeder, an automatic drinker, and straw pellets as bedding to ensure the same feeding environment. The control group was fed with a basal diet (CS) using the Broiler chicken compound diet 510 (Guiyang Special Drive Hope Agricultural Science and Technology Co., LTD, Guiyang, China). In addition, the treatment group was fed a basal diet supplemented with $0.8 \%$ EUE according to the relevant literature [37,44]. The basal diet ingredients are presented in Table 2. In order to investigate the repeated response 
of the chicks to the low-temperature environment and avoid long-term low-temperature stress leading to the death of the chicks, the environmental temperature control design was carried out according to the relevant literature [45]. Chicks of the above two groups were exposed to $10 \pm 1{ }^{\circ} \mathrm{C}$ from 22:00 to 6:00 to simulate cold stress, and returned to a normal temperature at $25 \pm 1^{\circ} \mathrm{C}$ from 6:00 to 22:00; this lasted for $15 \mathrm{~d}$. The relative humidity was $65 \pm 5 \%$ and the light:dark cycle was $10 \mathrm{~h}: 14 \mathrm{~h}$ per day. Water and feed were provided ad libitum to the chicks.

Table 2. Ingredient composition and calculated nutrient content of the basal diets.

\begin{tabular}{cccc}
\hline Ingredient, $\%$ & \multicolumn{3}{c}{ Nutrients $\mathbf{~}^{\mathbf{,} \%}$} \\
\hline corn & 58.5 & Metabolizable energy, kcal/kg & 3130 \\
Wheat bran & 3.20 & Crude protein & 22.1 \\
Soybean meal & 27.5 & Crude fiber & 3.56 \\
fish meal & 3.10 & Crude ash & 6.80 \\
Soyabean oil & 4.22 & Total phosphorus & 0.690 \\
Dicalcium phosphate & 2.14 & Available phosphorus & 0.530 \\
Sodium chloride & 0.420 & Methionine & 0.430 \\
DL-methionine & 0.350 & Calcium & 1.06 \\
L-Lysine·HCl & 0.270 & Met & 0.430 \\
Vitamin/mineral premix & 0.300 & & \\
Total & 100 & & \\
\hline
\end{tabular}

${ }^{1}$ Provided the following nutrients per kg of diet: Vitamin A, $6000 \mathrm{IU}$; vitamin D3, $800 \mathrm{IU}$; vitamin E, $20 \mathrm{IU}$, vitamin K3, 2 mg; vitamin B2, 2 mg;Cu, 21 mg; Fe, 100 mg; Zn, 60 mg; Mn, 90 mg; I, 1.0 mg; Co, 0.3 mg and Se, $0.3 \mathrm{mg} .{ }^{2}$ All data are the results of chemical analysis con-ducted in triplicate.

\subsection{Growth Performance}

The BW and feed intake (FI) of each replicate were recorded at $0 \mathrm{~d}, 7 \mathrm{~d}$, and $15 \mathrm{~d}$. The ADG, average feed intake (AFI), and F/G were calculated for $0-7 d, 8-15 d$, and $0-15 \mathrm{~d}$, respectively. The mortality rate was recorded daily and was used to calculate the mortality-corrected FCR.

\subsection{Antioxidant Index and Malondialdehyde Content}

At $0 \mathrm{~d}, 7 \mathrm{~d}$, and $15 \mathrm{~d}, 5$ chicks in each repeated group were slaughtered and sampled (15 chicks in each group, with a total of 90 chicks). Blood was collected from the jugular vein and placed in the procoagulant tube. After standing for $1-2 \mathrm{~h}$ at $4{ }^{\circ} \mathrm{C}$, the samples were centrifuged for $10 \mathrm{~min}$ at $4{ }^{\circ} \mathrm{C}(3000 \mathrm{rpm})$ to separate the serum. Five chicks' serum from each replicate group was mixed (in equal quantity) $(n=15)[46,47]$. The levels of total antioxidant capability (T-AOC), superoxide dismutase (SOD), glutathione-peroxidase (GSH-Px), and malondialdehyde (MDA) in serum were individually determined using the protein or MDA enzyme-linked immunosorbent assay (ELISA)kits (Nanjing Jiancheng Bioengineering Institute, Nanjing, China). The operation was carried out according to the manufacturer's instructions and repeated three times.

\subsection{Immune Index}

The levels of $\operatorname{IgA}, \operatorname{IgG}$, and IgM contents in chick serum were measured at $0 \mathrm{~d}, 7 \mathrm{~d}$, and $15 \mathrm{~d}$. The collection procedure of the serum sample was the same as above $(n=15)$. Total IgA, IgG, and IgM in serum were respectively determined by immunoglobulin ELISA kits (Shanghai Jining Biological Technology Co., Ltd., Shanghai, China). The operation was carried out according to the manufacturer's instructions and repeated three times.

\subsection{Determination of Organ Index}

One chick from each replicate representing the mean weight of the pen was selected, slaughtered, and eviscerated $(n=3)$. The liver, heart, spleen, thymus, bursa of Fabricius $(\mathrm{BF})$, duodenum, and musculature were separated and sucked with filter paper. After the 
blood had dried, their weights were valued, and the organ indexes were then calculated as follows [48]: Organ index = organ weight $(\mathrm{g}) /$ body weight $(\mathrm{g}) \times 100 \%$.

\subsection{Histopathological Examination}

When slaughtered at $15 \mathrm{~d}$, heart, liver, and duodenum samples were collected from 1 chick in each replicate for histological analysis $(n=3)$. The tissues were fixed in tissue fixative (Wuhan Saiweier Biological Technology Co., Ltd., Wuhan, China) for $24 \mathrm{~h}$ and later dehydrated by consecutive washes with ethyl alcohol (70-100\%). Subsequently, xylol was used to diaphanize the samples, then embedded in paraffin wax, and serial paraffin sections $(4 \mu \mathrm{m})$ were obtained. The sections were cut by a microtome and fixed on slides. Sections were stained with hematoxylin and eosin (H\&E) (Beyotime, Shanghai, China) and then observed under a microscope.

\subsection{Statistical Analysis}

Data analysis, single-factor ANOVA, and Duncan's multiple comparisons were performed using Microsoft Excel Tools and SAS 9.4 software (SAS Institute Inc., Cary, NC, USA) for comparing the differences in growth performance, antioxidant, and immune ability between the EUE group and control group. Results were presented as mean values \pm standard deviation (SD). Probability values of $p<0.05$ were considered statistically significant.

\section{Results}

\subsection{The Composition of EUE and EUL}

A total of 21 compounds were putatively identified in the EUE and EUL using LCMS analysis, including six iridoids, five flavonoids, four Phenylpropanoids, two lignans, and four others (Table 3). Results showed that the contents of active ingredients in the extract were all higher than that of leaves. Iridoids were abundant in the extract, among which the highest content of genipin was $56.2 \mathrm{mg} / \mathrm{g}$, followed by asperulosidic acid with $50.5 \mathrm{mg} / \mathrm{g}$, was well as aucubin with $17.1 \mathrm{mg} / \mathrm{g}$, eucommiol with $1.71 \mathrm{mg} / \mathrm{g}$, catalpol with $1.53 \mathrm{mg} / \mathrm{g}$, and eucommiside with $0.560 \mathrm{mg} / \mathrm{g}$. The content of the flavonoids kaempferol, isoquercitrin, kaempferol-3-O-rutinoside, quercetin, and rutin in EUE was $21.8 \mathrm{mg} / \mathrm{g}$, $1.68 \mathrm{mg} / \mathrm{g}, 21.8 \mathrm{mg} / \mathrm{g}, 1.68 \mathrm{mg} / \mathrm{g}, 1.36 \mathrm{mg} / \mathrm{g}, 0.960 \mathrm{mg} / \mathrm{g}$, and $0.110 \mathrm{mg} / \mathrm{g}$ respectively, and their contents were about 10 times that of EUL. Phenylpropanoids including chlorogenic acid, methyl chlorogenate, neochlorogenic acid, and cryptochlorogenic acid were all found in both EUE and EUL. Among them, the content of chlorogenic acid was the highest, at $36.8 \mathrm{mg} / \mathrm{g}$ in EUE but only $2.84 \mathrm{mg} / \mathrm{g}$ in EUL. The lignin substances of terpineol and 8-Hydroxypinoresinol were also detected in two samples. The EUE possessed a high content of $36.7 \mathrm{mg} / \mathrm{g}$ of total isomaltose compared to EUL (3.60 mg/g). In addition, 5Hydroxymethylfurfural, caffeic acid, and medioresil were also detected in EUE and EUL. Results indicated that EUE contained the same active ingredients as EUL. Moreover, the contents of active ingredients of EUE were all higher than EUL.

\subsection{Growth Performance under Cold Stress}

According to Table 4 , the initial BW of chicks did not differ $(p>0.05)$ between dietary treatments. After being fed EUE, the BW of chicks at $7 \mathrm{~d}$ and $15 \mathrm{~d}$ was significantly higher than that of the control group by $65.0 \mathrm{~g}(p=0.001)$ and $78.0 \mathrm{~g}(p<0.001)$, respectively. The chicks fed EUE had a greater average daily weight gain (ADG) than control chicks from days 0 to $7(p<0.001)$ and 0 to $15(p<0.001)$. It has been demonstrated that feeding EUE can significantly increase the BW and ADG of chicks under cold stress. 
Table 3. Components and contents of EUE and EUL.

\begin{tabular}{|c|c|c|c|}
\hline \multirow{2}{*}{ Components } & \multirow{2}{*}{ Compounds } & EUE & EUL \\
\hline & & \multicolumn{2}{|c|}{ Contents (mg/g) } \\
\hline \multirow{6}{*}{ Iridoids } & Genipin & 56.2 & 5.81 \\
\hline & Asperulosidic acid & 50.5 & 5.42 \\
\hline & Aucubin & 17.1 & 1.14 \\
\hline & Catalpol & 1.53 & 0.090 \\
\hline & Eucommiol & 1.71 & 0.090 \\
\hline & Eucommiside & 0.560 & 0.040 \\
\hline \multirow{5}{*}{ Flavonoids } & Kaempferol & 21.8 & 2.12 \\
\hline & Isoquercitrin & 1.68 & 0.120 \\
\hline & Kaempferol-3-O-rutinoside & 1.36 & 0.080 \\
\hline & Quercetin & 0.960 & 0.060 \\
\hline & Rutin & 0.110 & 0.007 \\
\hline \multirow{3}{*}{ Phenylpropanoids } & Chlorogenic acid & 37.0 & 2.84 \\
\hline & Methyl chlorogenate & 0.510 & 0.030 \\
\hline & Neochlorogenic acid & 0.480 & 0.030 \\
\hline \multirow{3}{*}{ Lignans } & Cryptochlorogenic acid & 0.240 & 0.020 \\
\hline & Terpineol & 2.60 & 0.130 \\
\hline & 8-Hydroxypinoresinol & 0.900 & 0.050 \\
\hline \multirow{4}{*}{ Other compounds } & Isomaltose & 36.7 & 3.56 \\
\hline & 5-Hydroxymethylfurfural & 2.47 & 0.130 \\
\hline & Caffeic acid & 0.280 & 0.020 \\
\hline & Medioresil & 1.44 & 0.120 \\
\hline
\end{tabular}

Table 4. The weight change of chicks under cold stress.

\begin{tabular}{|c|c|c|c|c|c|c|}
\hline \multirow{2}{*}{ Group } & \multicolumn{3}{|c|}{ Body Weight (g) } & \multicolumn{3}{|c|}{ Average Daily Gain (g) } \\
\hline & $0 \mathrm{~d}$ & $7 \mathrm{~d}$ & $15 \mathrm{~d}$ & $0-7 \mathrm{~d}$ & $8-15 d$ & $0-15 d$ \\
\hline CS & $200 \pm 8.16^{a}$ & $310 \pm 8.16^{b}$ & $493 \pm 4.71^{\mathrm{C}}$ & $13.8 \pm 0.000$ & $22.9 \pm 0.590$ & $18.3 \pm 0.290$ \\
\hline EUE & $198 \pm 2.36^{a}$ & $375 \pm 4.08^{b *}$ & $572 \pm 8.50^{\mathrm{c} *}$ & $22.1 \pm 0.290$ * & $24.6 \pm 0.590$ & $23.3 \pm 1.40 *$ \\
\hline$p$-value & 0.7952 & 0.0005 & 0.0003 & $<0.0001$ & 0.0474 & 0.0001 \\
\hline
\end{tabular}

Symbol * indicates a significant difference at $p<0.05$ between the Eucommia ulmoides group and the control group at the same time. $a, b, c$ Values with different letters within the same row are significantly different $(p<0.05)$. Values are the mean \pm SEM. Results are means of 15 samples obtained from the test chicks of each control and experimental group.

The AFI and F/G of chicks under cold stress are shown in Table 4 . The AFI in the EUE group was higher than that of the CS control group between days 0 and $7(p<0.001)$. However, the AFI of the EUE group was lower than that of the control group between days 8 and 15 ( $p=0.001)$. It was observed that the EUE extractive feeding was beneficial for the increase in feed intake at the early stage ( $0-7 \mathrm{~d})$, and may cause a decrease in intake over 8-15 d. It appeared that chicks in the group fed the extract gained a lower feed-to-gain ratio $(\mathrm{F} / \mathrm{G})$ than the controls under cold stress (Table 5). The F/G of chicks fed the extract were significantly lower by $32.8 \%, 9.70 \%$, and $21.7 \%$ than the control chicks at $0-7 \mathrm{~d}(p<0.001)$, 8-15 d $(p<0.01)$, and 0-15 d ( $p<0.001)$. Results showed EUE could reduce the chicks' F/G and improve the feed efficiency under cold stress. 
Table 5. The AFI and F/G of chicks under cold stress.

\begin{tabular}{|c|c|c|c|c|c|c|}
\hline \multirow{2}{*}{ Group } & \multicolumn{3}{|c|}{ Average Feed Intake (g) } & \multicolumn{3}{|c|}{ Feed to Gain Ratio } \\
\hline & $0-7 \mathrm{~d}$ & $8-15 d$ & 0-15 d & $0-7 \mathrm{~d}$ & $8-15 d$ & $0-15 d$ \\
\hline CS & $43.5 \pm 0.160$ & $61.4 \pm 0.650$ & $52.4 \pm 0.850$ & $3.17 \pm 0.020$ & $2.68 \pm 0.070$ & $2.86 \pm 0.050$ \\
\hline EUE & $47.2 \pm 0.010$ * & $57.2 \pm 0.050$ * & $52.2 \pm 1.13$ & $2.13 \pm 0.030 *$ & $2.42 \pm 0.060$ * & $2.24 \pm 0.040$ * \\
\hline$p$-value & 0.0001 & 0.0010 & 0.7908 & $<0.0001$ & 0.0050 & 0.0001 \\
\hline
\end{tabular}

Symbol * indicates a significant difference at $p<0.05$ between the Eucommia ulmoides group and the control group at the same time. Values are the mean \pm SEM. Results are means of 15 samples obtained from the test chicks of each control and experimental group. AFI: Average Feed Intake; F/G: Feed-to-Gain Ratio.

\subsection{Antioxidant Parameters under Cold Stress}

The level of T-AOC, SOD, GSH-Px, and MDA of chick supplied different feeds were detected on $0 \mathrm{~d}, 7 \mathrm{~d}$ and $15 \mathrm{~d}$ (Table 6). They were no significant differences among the groups before cold stress exposure. However, these indicators changed significantly in feeding at $7 \mathrm{~d}$ or $15 \mathrm{~d}$. The T-AOC of the EUE group increased by $13.4 \%(p<0.05)$ and $24.4 \%(p<0.05)$ at $0-7 \mathrm{~d}$ and $0-15 \mathrm{~d}$, respectively. In the CS group, T-AOC increased by $6.86 \%$ at $0-7 \mathrm{~d}(p<0.05)$ and $10.1 \%$ at $0-15 \mathrm{~d}(p<0.05)$, showing a higher change than the EUE group. Similarly, The SOD of the EUE group (increased by $11.4 \%$ and $29.5 \%, p<0.05$ ) also presented a lower change than the CS group (increased by $7.91 \%$ and $21.1 \%, p<0.05$ ) at $0-7 \mathrm{~d}$ and $0-15 \mathrm{~d}$. In addition, the SOD of the EUE group was significantly higher than the CS group at $15 \mathrm{~d}(p<0.05)$. The GSH-Px of the EUE group (reduced by $7.08 \%$ and $17.5 \%, p<0.05$ ) had a lower rate of decline than the CS group (reduced by $16.6 \%$ and $19.5 \%$, $p<0.05$ ) at $0-7 \mathrm{~d}$ and $0-15 \mathrm{~d}$. Meanwhile, The GSH-Px of the EUE group was $12.3 \%$ higher than the CS group at $7 \mathrm{~d}(p<0.01)$. The MDA of the EUE group was significantly lower by $22.5 \%$ than the CS group at $15 \mathrm{~d}(p<0.01)$.

Table 6. The oxidative and antioxidative indicators in chick serum under cold stress.

\begin{tabular}{|c|c|c|c|c|}
\hline Index & Group & $0 \mathrm{~d}$ & $7 \mathrm{~d}$ & $15 \mathrm{~d}$ \\
\hline \multirow{2}{*}{ T-AOC (U/mL) } & $\mathrm{CS}$ & $9.04 \pm 0.110^{\mathrm{a}}$ & $9.66 \pm 0.150^{\mathrm{a}}$ & $9.95 \pm 0.910^{\mathrm{a}}$ \\
\hline & EUE & $9.08 \pm 0.150^{\mathrm{a}}$ & $10.3 \pm 0.310^{b}$ & $11.3 \pm 0.210^{c}$ \\
\hline$p$-value & / & 0.7638 & 0.0552 & 0.1092 \\
\hline \multirow{2}{*}{$\mathrm{SOD}(\mathrm{U} / \mathrm{mL})$} & $\mathrm{CS}$ & $83.4 \pm 0.240^{\mathrm{a}}$ & $90.0 \pm 3.12^{b}$ & $101 \pm 1.72^{c}$ \\
\hline & EUE & $82.6 \pm 0.950^{a}$ & $92.0 \pm 2.89^{b}$ & $107 \pm 1.95^{c *}$ \\
\hline$p$-value & / & 0.2192 & 0.4770 & 0.0126 \\
\hline \multirow{2}{*}{ GSH-Px (U) } & CS & $421 \pm 7.22^{\mathrm{a}}$ & $351 \pm 6.52^{b}$ & $339 \pm 11.2^{c}$ \\
\hline & EUE & $424 \pm 7.77^{\mathrm{a}}$ & $394 \pm 9.41^{b *}$ & $350 \pm 5.77^{c}$ \\
\hline$p$-value & / & 0.7330 & 0.0029 & 0.2056 \\
\hline MDA & CS & $2.22 \pm 0.390^{\mathrm{a}}$ & $5.42 \pm 0.380^{b}$ & $4.72 \pm 0.140^{c}$ \\
\hline$(\mathrm{nmol} / \mathrm{mL})$ & EUE & $2.05 \pm 0.250^{\mathrm{a}}$ & $5.25 \pm 0.250^{b}$ & $3.66 \pm 0.240^{\mathrm{c} *}$ \\
\hline$p$-value & / & 0.5593 & 0.5614 & 0.0029 \\
\hline
\end{tabular}

Symbol * indicates a significant difference at $p<0.05$ between the Eucommia ulmoides group and the control group at the same time. ${ }^{a, b, c}$ Values with different letters within the same row are significantly different $(p<0.05)$. Values are the mean \pm SEM. Results are means of 15 samples obtained from the test chicks of each control and experimental group.

\subsection{Immune System Traits under Cold Stress}

The IgA, IgG, and IgM in serum of $0 \mathrm{~d}, 7 \mathrm{~d}$, and $15 \mathrm{~d}$ chicks were detected and presented in Table 7. The IgA of the EUE group was clearly higher by $6 \mu \mathrm{g} / \mathrm{mL}$ than the control group at $7 \mathrm{~d}(p<0.05)$. The IgG of the EUE group significantly increased by $93.0 \mu \mathrm{g} / \mathrm{mL}(p<0.01)$ and $280 \mu \mathrm{g} / \mathrm{mL}(p<0.001)$ when compared to the CS group at $7 \mathrm{~d}$ and $15 \mathrm{~d}$. The IgM of the EUE group was higher by $44.0 \mu \mathrm{g} / \mathrm{mL}(p<0.001)$ than the CS group at $15 \mathrm{~d}$. 
Table 7. The immune parameter status of chicks under cold stress.

\begin{tabular}{|c|c|c|c|c|}
\hline Index & Group & $0 \mathrm{~d}$ & $7 \mathrm{~d}$ & $15 \mathrm{~d}$ \\
\hline \multirow{2}{*}{$\operatorname{IgA}(\mu \mathrm{g} / \mathrm{mL})$} & CS & $359 \pm 4.59^{\mathrm{a}}$ & $409 \pm 2.37^{b}$ & $305 \pm 8.19^{c}$ \\
\hline & EUE & $353 \pm 6.26^{a}$ & $415 \pm 2.86^{b *}$ & $315 \pm 1.74^{c}$ \\
\hline$p$-value & / & 0.2477 & 0.0397 & 0.1114 \\
\hline \multirow{2}{*}{$\operatorname{IgG}(\mu \mathrm{g} / \mathrm{mL})$} & $\mathrm{CS}$ & $2419 \pm 26.5^{\mathrm{a}}$ & $3069 \pm 20.0^{b}$ & $2109 \pm 62.5^{c}$ \\
\hline & EUE & $2409 \pm 51.7^{\mathrm{a}}$ & $3162 \pm 15.3^{b *}$ & $2389 \pm 30.0^{\mathrm{c} *}$ \\
\hline$p$-value & / & 0.7812 & 0.0030 & $<0.0001$ \\
\hline \multirow{2}{*}{$\operatorname{IgM}(\mu \mathrm{g} / \mathrm{mL})$} & CS & $600 \pm 1.70^{a}$ & $713 \pm 5.88^{b}$ & $846 \pm 7.78^{c}$ \\
\hline & EUE & $603 \pm 4.49^{\mathrm{a}}$ & $721 \pm 1.70^{b}$ & $890 \pm 7.40^{c *}$ \\
\hline$p$-value & / & 0.3486 & 0.0907 & $<0.0001$ \\
\hline
\end{tabular}

Symbol * indicates a significant difference at $p<0.05$ between the Eucommia ulmoides group and the control group at the same time. ${ }^{a, b, c}$ Values with different letters within the same row are significantly different $(p<0.05)$ Values are the mean \pm SEM. Results are means of 15 samples obtained from the test chicks of each control and experimental group.

\subsection{Organ Development and Histopathology under Cold Stress}

According to experimental results, the EUE group tended to have higher organ indexes, including heart, liver, spleen, $\mathrm{BF}$, stomach, duodenum, and pancreatic, than the control group at $7 \mathrm{~d}$ and $15 \mathrm{~d}$, except at $7 \mathrm{~d}$ for the spleen index. Unfortunately, these differences were not significant (Table 8).

Table 8. The organ index of chicks under cold stress.

\begin{tabular}{cccccccc}
\hline & \multicolumn{7}{c}{ Organ Index } \\
\cline { 2 - 8 } Group & Heart & Liver & Spleen & $\begin{array}{c}\text { Bursa of } \\
\text { Fabricius }\end{array}$ & Stomach & Duodenum & Pancreatic \\
& & \multicolumn{7}{c}{$7 \mathrm{~d}$} \\
CS & $7.79 \pm 0.370$ & $45.2 \pm 0.370$ & $1.57 \pm 0.050$ & $3.19 \pm 0.050$ & $30.2 \pm 3.77$ & $21.3 \pm 1.00$ & $3.72 \pm 0.660$ \\
EUE & $7.93 \pm 0.220$ & $45.6 \pm 0.240$ & $1.55 \pm 0.030$ & $3.38 \pm 0.080$ & $31.1 \pm 0.120$ & $22.2 \pm 0.050$ & $3.77 \pm 0.030$ \\
$p$-value & 0.6775 & 0.2729 & 0.6460 & 0.0590 & 0.7624 & 0.2763 & 0.9189 \\
CS & $7.30 \pm 0.770$ & $39.6 \pm 0.990$ & $2.39 \pm 0.380$ & $3.28 \pm 0.050$ & $26.5 \pm 5.07$ & $14.5 \pm 2.62$ & $3.80 \pm 0.500$ \\
EUE & $7.85 \pm 0.360$ & $39.7 \pm 0.720$ & $2.87 \pm 0.310$ & $3.30 \pm 0.010$ & $28.0 \pm 1.72$ & $15.0 \pm 0.820$ & $4.27 \pm 0.650$ \\
$p$-value & 0.4107 & 0.9494 & 0.1912 & 0.6149 & 0.6979 & 0.8016 & 0.4677 \\
\hline
\end{tabular}

Values are the mean \pm SEM. Results are means of 3 samples obtained from the test chicks of each control and experimental group.

Results indicated that cold stress could damage the duodenum, heart, and stomach of chicks at $15 \mathrm{~d}$, clearly elucidating the disrupted duodenal villi structure and inflammation in the duodenum (Figure 1A,D). It was also observed that myocardial fibers were disordered and broken in the heart (Figure 1B,E) and stomach muscles, and fiber tissues were broken and erosion spots appeared (Figure 1C,F). However, the duodenum, heart, and stomach tissues of chicks in the EUE group were less damaged than the CS group. 

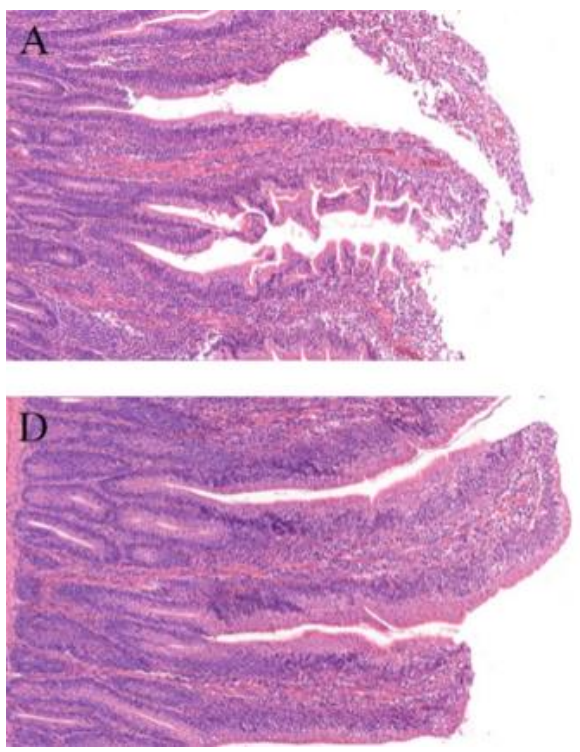
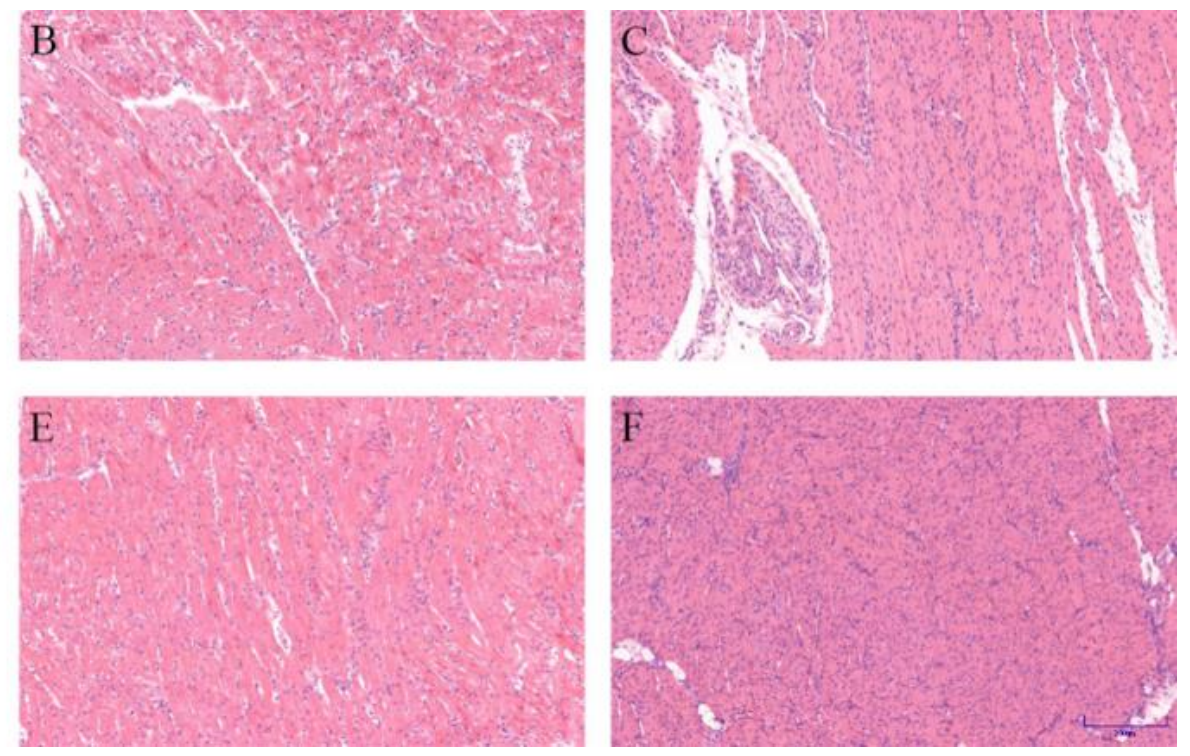

Figure 1. H\&E staining tissue sections of duodenum, heart, and stomach. (A-C) CS group (A): Duodenum; (B): Heart; (C): stomach. (D-F) EUE group (D): Duodenum; (E): Heart; (F): Stomach.

\section{Discussion}

Eucommia ulmoides is one of the traditional CHMs, which contains a variety of active ingredients in its root, bark, leaf, and flower, with multiple economic and pharmacological values [49-51]. The identification of Eucommia ulmoides and their extracts have been a hot spot in the research and utilization of Eucommia ulmoides. Our study showed that the water extract of EUL contained lignans, iridoids, phenylpropanoids, flavonoids, and so on, which is consistent with that extracted by organic solvent $[52,53]$. However, the water extract has the advantages of low cost, simple operation, and less pollution. It has been reported that iridoids, flavonoids, phenylpropanoids, and other substances in Eucommia ulmoides have antioxidant, anti-inflammatory, and immunity effects $[28,54,55]$. In addition, chlorogenic acid [36,37], quercetin [38], and rutin [56] increase immune and antioxidant capacity and promote animal growth and development. It was shown that EUE contained abundant chlorogenic acid, galangal, woodruff nucleoside acid, peach leaf coral glycosides, rutin, and quercetin, which may improve the immune function and growth performance of chicks, indicating EUE can be a potential feed additive.

Cold stress can reduce the growth performance of animals, such as BW and feed efficiency [57-59]. In the present study, the chicks supplemented with EUE showed better growth performance of higher BW $(p<0.01)$ and ADG $(p<0.05)$ and lower F/G $(p<0.001)$ throughout the study period, and higher AFI at $0-7 \mathrm{~d}(p<0.001)$. Our study showed EUE had a better protective effect on cold-stressed poultry. Studies have shown that feeding Eucommia ulmoides can improve animal growth performance [60]. Previous investigations found that after feeding Eucommia ulmoides (rich in chlorogenic acid), the weight of grass carp increased by $5.22 \%$, indicating that Eucommia ulmoides can promote the growth of grass carp [34]. It was reported earlier that adding $1 \mathrm{~g} / \mathrm{kg}$ rutin can improve the growth performance of broilers [61]. Additionally, the addition of EUE containing flavone improved the growth performance of piglets stimulated by dipterous [35]. The reason EUE can protect chicks under cold stress may be that EUE contains high levels of chlorogenic acid, rutin, flavonoids, etc., which promotes the BW, ADG, and AFI of chicks, decreases the $\mathrm{F} / \mathrm{G}$, and alleviates the impact of cold stress.

The body's antioxidant level reflects the ability to resist stress [62]. T-AOC, SOD, and GSH-Px in serum are all essential components of the antioxidant defense system, and they have very significant impacts on homeostasis between oxidation and antioxidants [63]; MDA is one of the end-products of lipid peroxidation, and its level reflects the degree 
of oxidative injury to the organism [64]. As reported, cold stress could cause an increase in T-AOC, SOD, and GSH-Px levels [65] and the reduction of MDA levels [66]. Previous studies reported that EUE improved the antioxidant capacity of weaned piglets [31,67]. Additionally, the dietary chlorogenic acid-enriched extract (CGAE) from Eucommia ulmoides supplementation improved oxidative status in pigs [60]. Bai et al. (2019) demonstrated that the addition of Eucommia ulmoides to diet could significantly increase GSH-Px activity and decrease MDA content, thus improving the antioxidant capacity of hemp ducks [41]. Chlorogenic acid and flavonoids are both natural antioxidants [68,69]. The chlorogenic acid-enriched extract (CGAE) from Eucommia ulmoides leaves significantly elevated T-AOC and SOD activity in the liver and serum of lambs under stress, reduced MDA content, improved antioxidant status, and alleviated oxidative damage of lambs [42]. The literature also shows that EUE (flavonoids) alleviates the oxidative stress induced by diquat in piglets by reducing the growth performance impairment, pro-inflammatory cytokines secretion, and intestinal barrier dysfunction [35]. In this study, the results showed that chicks fed with EUE could significantly increase the levels of SOD at $15 \mathrm{~d}(p<0.05)$ and GSH-Px at 7 $\mathrm{d}(p<0.01)$, and significantly reduce the level of MDA at $15 \mathrm{~d}(p<0.01)$. Thus, EUE can reduce the damage of cold stress to the chicks by improving the antioxidant ability, which may be related to chlorogenic acid and flavonoids in the antioxidant substances in EUE.

The variations of ambient temperature affect the immune response of chicks [70,71]. The immune system is often subject to low temperatures, which reduces the activity of immunoglobulins such as IgA, IgG, and IgM, resulting in immunosuppression in animals [72]. A previous study has shown that dietary EUL extracts significantly increase the blood IgG and IgM contents of weaned piglets [73] and broilers [74]. Additionally, Flavonoids extracted from Chinese herbs could improve immune function and alleviate immune stress in broilers challenged with lipopolysaccharide [75]. An animal's systemic immune status may be reflected by the concentration of $\operatorname{IgA}, \operatorname{IgG}$, and serum $\operatorname{IgM}$ [76]. In the present study, the level of IgA (7 d, $p<0.05)$, IgG (7d, $p<0.01 ; 15 \mathrm{~d}, p<0.001)$, and IgM (15 d, $p<0$. 001) in the EUE group were significantly higher than that in the CS group at the same stage under low temperatures. Our study suggests that EUE may enhance chicks' immune function by increasing the serum immunoglobulin contents ( $\operatorname{IgA}, \operatorname{Ig} G$, and $\operatorname{IgM})$, thus having a protective effect against cold stress on chicks.

The organ index often reflects the relative growth and functional state of organs [77]. The liver, spleen, and BF are important immune organs, and their organ indexes could reflect the immune function [78-82]. EUL extract could increase the liver index and contribute to the alleviation of the weaning stress response in piglets $[64,83]$. In addition, EUL extract can increase the index of spleen and BF and improve the immune function of hemp ducks [41]. The work presented here showed that EUE had no significant effects on the indexes of heart, liver, spleen, BF, stomach, duodenum, and pancreas of chicks under cold-stress conditions. Interestingly, we observed that, compared with the control group, the EUE group had a certain degree of improvement in all organ indexes except the spleen at $7 \mathrm{~d}$. To a certain extent, feeding EUE could reduce the effects of cold stress on the organ development of chicks. Unfortunately, the differences were not significant. The results may be related to the fact that only $0.8 \%$ EUE was added in this experiment.

The heart, duodenum, and stomach are essential organs for metabolism and nutrient absorption, and their health degree reflects the adaptability of an organism to environmental stress $[84,85]$. It has been reported that stresses such as cold exposure can induce heart, duodenum, and stomach injury $[9,86]$. In the present study, cold stress caused damage to the tissue of the heart, duodenum, and stomach by H\&E staining, while the damage in the EUE group was milder than the CS group. EUL extract can reduce weaned pigs' intestinal damage caused by stress [87]. Consistent with the aforementioned reports, we identified that EUE could reduce the organ damage of chicks under cold stress, which may be related to the EUE elevating metabolism and nutrient absorption and enhancing organ health. 


\section{Conclusions}

In summary, this study showed that EUE had obvious protective effects against chicks' cold stress. The dietary EUE supplementation improved the growth performance, antioxidant, and immune ability of chicks, and reduced organ damage caused by cold stress, to realize the protective effect of a water extract from Eucommia ulmoides on coldstressed chicks. These findings can provide a new control strategy for the bottleneck issue of chick production caused by cold stress, although further studies are needed to further explain the protection mechanism.

Author Contributions: Conceptualization, L.S., Y.L., M.L. and D.Z.; methodology, T.H., Q.L. and Y.L.; formal analysis, L.S. and T.H.; data curation, Q.L., Y.L. and M.L.; writing-original draft preparation, L.S., T.H. and Y.L.; writing-review and editing, L.S. and T.H.; supervision, L.S. and D.Z. All authors have read and agreed to the published version of the manuscript.

Funding: This research was funded by the Guizhou Province Graduate Research Fund YJSCXJH (2020)079, the Guizhou Province Science and Technology Plan Project (2018-4001-06).

Institutional Review Board Statement: Animal use and animal trials in this study have been approved by the Guizhou University Subcommittee of Experimental Animal Ethics.

Informed Consent Statement: Not applicable.

Data Availability Statement: The data that support the findings of this study are available from the corresponding author on reasonable request.

Acknowledgments: The author would like to thank Qin Lijun and Li Jianrong for their help in the processing of eucommia powder. And we also thank the many undergraduate students who aided in the collection of samples for this study, as well as the staff at the Guizhou University Plant and Animal Sciences Teaching, Research, and Education.

Conflicts of Interest: The authors have no conflicts of interest to declare.

\section{References}

1. Rastogi, S.; Haldar, C. Role of melatonin and HSF-1 \HSP-70 in modulating cold stress-induced immunosuppression in a tropical rodent- Funambulus pennanti (vol 87, 102456, 2020). J. Therm. Biol. 2021, 98, 102941. [CrossRef] [PubMed]

2. Yang, J.J.; Zhang, M.H.; Zhou, Y. Effects of selenium-enriched Bacillus sp. compounds on growth performance, antioxidant status, and lipid parameters breast meat quality of Chinese Huainan partridge chicks in winter cold stress. Lipids Health Dis. 2019, 18, 1-10. [CrossRef] [PubMed]

3. Roobol, A.; Carden, M.J.; Newsam, R.J.; Smales, C.M. Biochemical insights into the mechanisms central to the response of mammalian cells to cold stress and subsequent rewarming. FEBS J. 2009, 276, 286-302. [CrossRef] [PubMed]

4. Bellavance, M.A.; Rivest, S. The HPA-Immune axis and the immunomodulatory actions of glucocorticoics in the brain. Front. Immunol. 2014, 5, 136. [CrossRef]

5. Chowanski, S.; Lubawy, J.; Paluch-Lubawa, E.; Spochacz, M.; Rosinski, G.; Slocinska, M. The physiological role of fat body and muscle tissues in response to cold stress in the tropical cockroach Gromphadorhina coquereliana. PLoS ONE 2017, 12, e0173100. [CrossRef]

6. Zhang, Z.W.; Bi, M.Y.; Yao, H.D.; Fu, J.; Li, S.; Xu, S.W. Effect of Cold Stress on Expression of AMPK alpha-PPAR alpha Pathway and Inflammation Genes. Avian Dis. 2014, 58, 415-426. [CrossRef]

7. Liu, Y.; Yang, Y.Y.; Yao, R.Z.; Hu, Y.J.; Liu, P.; Lian, S.; Lv, H.M.; Xu, B.; Li, S.Z. Dietary supplementary glutamine and L-carnitine enhanced the anti-cold stress of Arbor Acres broilers. Arch. Anim. Breed. 2021, 64, 231-243. [CrossRef]

8. Sinclair, B.J.; Ferguson, L.V.; Salehipour-shirazi, G.; MacMillan, H.A. Cross-tolerance and Cross-talk in the Cold: Relating Low Temperatures to Desiccation and Immune Stress in Insects. Integr. Comp. Biol. 2013, 53, 545-556. [CrossRef]

9. Bhardwaj, A.; Sharma, P.; Mishra, J.; Misra, K. Lingzhi or Reishi Medicinal Mushroom, Ganoderma lucidum (Agaricomycetes), Mycelium Aqueous Extract Modulates High-Altitude-Induced Stress. Int. J. Med. Mushrooms 2019, 21, 443-458. [CrossRef]

10. Cai, J.H.; Yeh, T.F.; Wei, H.W.; Liu, I.H. Temperature-induced embryonic diapause in blue-breasted quail (Coturnix chinensis) correlates with decreased mitochondrial-respiratory network and increased stress-response network. Poult. Sci. 2019, 98, 2977-2988. [CrossRef]

11. Fathi, M.; Adl, K.N.; Nezhad, Y.E.; Shahryar, H.A.; Daneshyar, M.; Tanha, T. The Role of Oxidative Stress in Development of Congestive Heart Failure (CHF) in Broiler with Pulmonary Hypertension Syndrome (PHS). J. Anim. Vet. Adv. 2011, 10, 2724-2729.

12. Kim, C.H.; Kang, H.K.; Kim, H.S. Effect of dietary energy levels on growth performance, blood parameter and intestinal morphology of Pekin ducks in low ambient temperature. J. Anim. Sci. Technol. 2019, 61, 305-312. [CrossRef] 
13. Matsubara, T.; Shimamoto, S.; Ijiri, D.; Ohtsuka, A.; Kanai, Y.; Hirabayashi, M. The effects of acute cold exposure on morphology and gene expression in the heart of neonatal chicks. J. Comp. Physiol. B 2016, 186, 363-372. [CrossRef]

14. Zangeneh, S.; Torki, M.; Abdolmohammadi, A.; Saki, A. Dietary addition of lysophospholipids and vitamin C affects growth performance, serum metabolites, antioxidant capacity and carcass characteristics of broiler chickens reared under low ambient temperature. Anim. Prod. Sci. 2020, 60, 1557-1566. [CrossRef]

15. Kamanli, S.; Durmus, I.; Yalcin, S.; Yildirim, U.; Meral, O. Effect of prenatal temperature conditioning of laying hen embryos: Hatching, live performance and response to heat and cold stress during laying period. J. Therm. Biol. 2015, 51, 96-104. [CrossRef]

16. Wijnen, H.J.; Van den Brand, H.; Lammers, A.; van Roovert-Reijrink, I.A.M.; van der Pol, C.W.; Kemp, B.; Molenaar, R. Effects of eggshell temperature pattern during incubation on primary immune organ development and broiler immune response in later life. Poult. Sci. 2020, 99, 6619-6629. [CrossRef] [PubMed]

17. Kaneko, I.N.; Fernandes, J.I.M.; de Cristo, A.B.; da Cruz, F.K.; dos Santos, T.C. Effects of breeder age and short-term temperature stimulation during incubation on performance, organ weight, and carcass yield in male and female broilers. Semin-Cienc. Agrar. 2021, 42, 2569-2583. [CrossRef]

18. Nord, A.; Nilsson, J.A. Low incubation temperature slows the development of cold tolerance in a precocial bird. J. Exp. Biol. 2021, 224, jeb237743. [CrossRef] [PubMed]

19. Suarez-Perez, A.; Corbera, J.A.; Gonzalez-Martin, M.; Tejedor-Junco, M.T. Multidrug-Resistant Phenotypes of Escherichia coli Isolates in Wild Canarian Egyptian Vultures (Neophron percnopterus majorensis). Animals 2021, 11, 1692. [CrossRef] [PubMed]

20. Damaziak, K.; Musielak, M.; Musielak, C.; Riedel, J.; Gozdowski, D.; Grzybek, W. Effect of different rearing system on eggs production, hatchability, and offspring quality in layer breeders. Poult. Sci. 2021, 100, 101101. [CrossRef]

21. Van Limbergen, T.; Sarrazin, S.; Chantziaras, I.; Dewulf, J.; Ducatelle, R.; Kyriazakis, I.; McMullin, P.; Mendez, J.; Niemi, J.K.; Papasolomontos, S.; et al. Risk factors for poor health and performance in European broiler production systems. BMC Vet. Res. 2020, 16, 287. [CrossRef] [PubMed]

22. Cowley, J.M.; O'Donovan, L.A.; Burton, R.A. The composition of Australian Plantago seeds highlights their potential as nutritionally-rich functional food ingredients. Sci. Rep. 2021, 11, 12692. [CrossRef] [PubMed]

23. Azevedo, I.L.; Nogueira, W.C.L.; de Almeida, A.C.; Guedes, L.L.M.; Vieira, C.R.; Santos, S.H.S.; Carvalho, C.M.C.; da Fonseca, F.S.A.; de Souza, R.M.; de Souza, C.N. Antioxidant activity and chemical composition of meat from broilers fed diets containing different essential oils. Vet. World 2021, 14, 1638-1643. [CrossRef] [PubMed]

24. Arjin, C.; Hongsibsong, S.; Pringproa, K.; Seel-Audom, M.; Ruksiriwanich, W.; Sutan, K.; Sommano, S.R.; Sringarm, K. Effect of Ethanolic Caesalpinia sappan Fraction on In Vitro Antiviral Activity against Porcine Reproductive and Respiratory Syndrome Virus. Vet. Sci. 2021, 8, 106. [CrossRef]

25. Alagawany, M.; El-Saadony, M.T.; Elnesr, S.S.; Farahat, M.; Attia, G.; Madkour, M.; Reda, F.M. Use of lemongrass essential oil as a feed additive in quail's nutrition: Its effect on growth, carcass, blood biochemistry, antioxidant and immunological indices, digestive enzymes and intestinal microbiota. Poult. Sci. 2021, 100, 101172. [CrossRef] [PubMed]

26. Yan, Y.; Zhao, H.; Chen, C.H.; Zou, L.S.; Liu, X.H.; Chai, C.; Wang, C.C.; Shi, J.J.; Chen, S.Y. Comparison of Multiple Bioactive Constituents in Different Parts of Eucommia ulmoides Based on UFLC-QTRAP-MS/MS Combined with PCA. Molecules 2018, 23, 643. [CrossRef]

27. Xu, J.; Hou, H.; Hu, J.; Liu, B. Optimized microwave extraction, characterization and antioxidant capacity of biological polysaccharides from Eucommia ulmoides Oliver leaf. Sci. Rep. 2018, 8, 6561. [CrossRef]

28. Liu, C.; Guo, F.F.; Xiao, J.P.; Wei, J.Y.; Tang, L.Y.; Yang, H.J. Research advances in chemical constituents and pharmacological activities of different parts of Eucommia ulmoides. Zhongguo Zhong Yao Za Zhi 2020, 45, 497-512. [CrossRef]

29. Jiang, Y.; Liu, R.; Chen, J.; Liu, M.; Liu, M.; Liu, B.; Yi, L.; Liu, S. Application of multifold characteristic ion filtering combined with statistical analysis for comprehensive profiling of chemical constituents in anti-renal interstitial fibrosis I decoction by ultra-high performance liquid chromatography coupled with hybrid quadrupole-orbitrap high resolution mass spectrometry. J. Chromatogr. A 2019, 1600, 197-208. [CrossRef]

30. Zhao, X.; Wang, Y.; Nie, Z.; Han, L.; Zhong, X.; Yan, X.; Gao, X. Eucommia ulmoides leaf extract alters gut microbiota composition, enhances short-chain fatty acids production, and ameliorates osteoporosis in the senescence-accelerated mouse P6 (SAMP6) model. Food Sci. Nutr. 2020, 8, 4897-4906. [CrossRef]

31. Liao, W.S.; Zhao, S.S.; Yang, Z.B.; Yang, W.R.; Huang, L.B.; Liu, F.X.; Liu, M.; Ge, J.S.; Wang, Y.X.; Jiang, S.Z. Illicium verum and Eucommia ulmoides leaf extracts promote nutrient availability and antioxidant capacity in piglets by upregulating duodenal and jejunal Nrf2/TNF-alpha. J. Anim. Physiol. Anim. Nutr. 2021, 105, 916-926. [CrossRef]

32. Feng, H.B.; Yang, X.N.; Fan, J.; Zhang, L.Z.; Liu, Q.Q.; Chai, D.K. DEC-205 receptor-mediated long-circling nanoliposome as an antigen and Eucommia ulmoides polysaccharide delivery system enhances the immune response via facilitating dendritic cells maturation. Drug Deliv. 2020, 27, 1581-1596. [CrossRef]

33. Li, L.; Liu, M.H.; Shi, K.; Yu, Z.J.; Zhou, Y.; Fan, R.S.; Shi, Q.Q. Dynamic Changes in Metabolite Accumulation and the Transcriptome during Leaf Growth and Development in Eucommia ulmoides. Int. J. Mol. Sci. 2019, 20, 4030. [CrossRef]

34. Sun, W.T.; He, M.; Xu, X.Y.; Li, X.Q.; Pan, W.Q.; Leng, X.J. Comparison study of three compounds in Eucommia ulmoides on growth, flesh quality of grass carp (Ctenopharyngodon idella). Aquacult. Nutr. 2019, 25, 906-916. [CrossRef]

35. Yuan, D.; Hussain, T.; Tan, B.; Liu, Y.; Ji, P.; Yin, Y. The Evaluation of Antioxidant and Anti-Inflammatory Effects of Eucommia ulmoides Flavones Using Diquat-Challenged Piglet Models. Oxid. Med. Cell Longev. 2017, 2017, 8140962. [CrossRef] [PubMed] 
36. Teng, Z.W.; Wang, L.F.; Du, H.Y.; Yang, G.Q.; Fu, T.; Lian, H.X.; Sun, Y.; Liu, S.H.; Zhang, L.Y.; Gao, T.Y. Metabolomic and Lipidomic Approaches to Evaluate the Effects of Eucommia ulmoides Leaves on Milk Quality and Biochemical Properties. Front. Vet. Sci. 2021, 8, 644967. [CrossRef] [PubMed]

37. Zhao, J.S.; Deng, W.; Liu, H.W. Effects of chlorogenic acid-enriched extract from Eucommia ulmoides leaf on performance, meat quality, oxidative stability, and fatty acid profile of meat in heat-stressed broilers. Poult. Sci. 2019, 98, 3040-3049. [CrossRef] [PubMed]

38. Yang, H.; Li, X.Q.; Xu, Z.; Cheng, Z.; Leng, X.J. Effects of three active components inEucommia ulmoideson growth and flesh quality of grass carp (Ctenopharyngodon idellus) based on transcriptomics. Aquacult. Nutr. 2020, 26, 1895-1907. [CrossRef]

39. Khan, S.A.; Naeem, R.; Hussain, S.; Ali, S.; Muhammad, N.; Hussain, Z.; Shujah, S. Antimicrobial and antiurease potential of Diorganotin (IV) Schiff bases. Pak. J. Pharm. Sci. 2018, 31, 1399-1405. [PubMed]

40. Yuan, D.X.; Wang, J.; Xiao, D.F.; Li, J.F.; Liu, Y.H.; Tan, B.; Yin, Y.L. Eucommia ulmoides Flavones as Potential Alternatives to Antibiotic Growth Promoters in a Low-Protein Diet Improve Growth Performance and Intestinal Health in Weaning Piglets. Animals 2020, 10, 1998. [CrossRef]

41. Bai, L.; Song, X.; Fu, Y.P.; Chen, S.F.; Tian, Y.; Jia, R.Y.; Zou, Y.F.; Li, L.X.; Liang, X.X.; He, C.L.; et al. Effects of a mixed extract of Cortex Fraxini, Pulsatilla chinensis, and Eucommia ulmoides on immunity and antioxidant activity in hemp ducks. Livest. Sci. 2019, 221, 63-69. [CrossRef]

42. Liu, H.W.; Zhao, J.S.; Li, K.; Deng, W. Effects of chlorogenic acids-enriched extract from Eucommia ulmoides leaves on growth performance, stress response, antioxidant status and meat quality of lambs subjected or not to transport stress. Anim. Feed. Sci. Tech. 2018, 238, 47-56. [CrossRef]

43. Chuang, W.Y.; Lin, W.C.; Hsieh, Y.C.; Huang, C.M.; Chang, S.C.; Lee, T.T. Evaluation of the Combined Use of Saccharomyces Cerevisiae and Aspergillus Oryzae with Phytase Fermentation Products on Growth, Inflammatory, and Intestinal Morphology in Broilers. Animals 2019, 9, 1051. [CrossRef] [PubMed]

44. Wang, M.Q.; Du, Y.J.; Ye, S.S.; Tao, W.J.; Wang, C. Effects of Duzhong (Eucommia ulmoides Oliv.) on Growth Performance and Meat Quality in Broiler Chicks. J. Anim. Vet. Adv. 2012, 11, 1385-1389. [CrossRef]

45. Mohammed, A.A.; Jacobs, J.A.; Murugesan, G.R.; Cheng, H.W. Effect of dietary synbiotic supplement on behavioral patterns and growth performance of broiler chickens reared under heat stress. Poult. Sci. 2018, 97, 1101-1108. [CrossRef]

46. Guang, Y.; Feng, D.; Li, Y.Z.; Hui, L. Theoretical and Experimental Evidence in Mixed Serum Samples as Natural Reference Materials for Measuring Activity of Biomacromolecules in Serum. Clin. Lab. 2016, 62, 2429-2436. [CrossRef]

47. Chen, Y.-D.; Wang, J.-J.; Zhou, C.-H.; Xu, L.-Q. Study on the mixed testing of serum samples in seroepidemiological survey of parasitic diseases. Zhonghua Liu Xing Bing Xue Za Zhi = Zhonghua Liuxingbingxue Zazhi 2006, 27, 947-949.

48. Hu, R.J.; Liu, H.J.; Wang, M.M.; Li, J.; Lin, H.; Liang, M.Y.; Gao, Y.P.; Yang, M.M. An OMV-Based Nanovaccine Confers Safety and Protection against Pathogenic Escherichia coli via Both Humoral and Predominantly Th1 Immune Responses in Poultry. Nanomaterials 2020, 10, 2293. [CrossRef]

49. Koh, W.; Shin, J.S.; Lee, J.; Lee, I.H.; Lee, S.K.; Ha, I.H.; Chung, H.J. Anti-inflammatory effect of Cortex Eucommiae via modulation of the toll-like receptor 4 pathway in lipopolysaccharide-stimulated RAW 264.7 macrophages. J. Ethnopharmacol. 2017, 209, 255-263. [CrossRef]

50. Fang, C.; Chen, L.Y.; He, M.Z.; Luo, Y.Y.; Zhou, M.J.; Zhang, N.; Yuan, J.F.; Wang, H.L.; Xie, Y.Y. Molecular mechanistic insight into the anti-hyperuricemic effect of Eucommia ulmoides in mice and rats. Pharm. Biol. 2019, 57, 112-119. [CrossRef]

51. Wang, C.Y.; Tang, L.; He, J.W.; Li, J.; Wang, Y.Z. Ethnobotany, Phytochemistry and Pharmacological Properties of Eucommia ulmoides: A Review. Am. J. Chin. Med. 2019, 47, 259-300. [CrossRef]

52. Du, K.Z.; Li, J.; Wang, L.H.; Hao, J.; Yang, X.J.; Gao, X.M.; Chang, Y.X. Biosurfactant trehalose lipid-enhanced ultrasound-assisted micellar extraction and determination of the main antioxidant compounds from functional plant tea. J. Sep. Sci. 2020, 43, 799-807. [CrossRef] [PubMed]

53. Yu, L.; Cao, L.; Chang, Y.H.; Duan, C.J.; Liu, C.; Zhao, X.L.; Yue, G.L.; Wang, X.Q.; Fu, Y.J. Enhanced extraction performance of iridoids, phenolic acids from Eucommia ulmoides leaves by tailor-made ternary deep eutectic solvent. Microchem. J. 2021, 161, 105788. [CrossRef]

54. Huang, A.G.; Tan, X.P.; Cui, H.B.; Qi, X.Z.; Zhu, B.; Wang, G.X. Antiviral activity of geniposidic acid against white spot syndrome virus replication in red swamp crayfish Procambarus clarkii. Aquaculture 2020, 528, 735533. [CrossRef]

55. Liu, W.Y.; Dong, Z.L.; Li, K.H.; Shao, F.H.; Shen, F.; Zhao, C.C.; Kang, X.D.; Cheng, K.Z. Secondary Metabolites from the Barks of Eucommia ulmoides and Their Bioactivities. J. Chem. Soc. Pak. 2019, 41, 169-174.

56. Zhang, Q.; Zhu, M.Q.; Zhang, J.F.; Su, Y.Q. Improved on-line high performance liquid chromatography method for detection of antioxidants in Eucommia ulmoides Oliver flower. J. Biosci. Bioeng. 2014, 118, 45-49. [CrossRef]

57. Li, C.C.; Peng, M.; Liao, M.; Guo, S.S.; Hou, Y.Q.; Ding, B.Y.; Wu, T.; Yi, D. Effects of N-acetylcysteine on the energy status and antioxidant capacity in heart and liver of cold-stressed broilers. Asian Australas. J. Anim. 2020, 33, 1444-1454. [CrossRef]

58. Zhou, H.J.; Kong, L.L.; Zhu, L.X.; Hu, X.Y.; Busye, J.; Song, Z.G. Effects of cold stress on growth performance, serum biochemistry, intestinal barrier molecules, and adenosine monophosphate-activated protein kinase in broilers. Animal 2021, 15, 100138. [CrossRef]

59. Coloma-Garcia, W.; Mehaba, N.; Such, X.; Caja, G.; Salama, A.A.K. Effects of Cold Exposure on Some Physiological, Productive, and Metabolic Variables in Lactating Dairy Goats. Animals 2020, 10, 2383. [CrossRef] 
60. Li, H.G.; Zhao, J.S.; Deng, W.; Li, K.; Liu, H.W. Effects of chlorogenic acid-enriched extract from Eucommia ulmoides Oliver leaf on growth performance and quality and oxidative status of meat in finishing pigs fed diets containing fresh or oxidized corn oil. J. Anim. Physiol. Anim. Nutr. 2020, 104, 1116-1125. [CrossRef]

61. Hassan, F.A.M.; Roushdy, E.M.; Kishawy, A.T.Y.; Zaglool, A.W.; Tukur, H.A.; Saadeldin, I.M. Growth Performance, Antioxidant Capacity, Lipid-Related Transcript Expression and the Economics of Broiler Chickens Fed Different Levels of Rutin. Animals 2018, 9, 7. [CrossRef]

62. Cao, S.P.; Zhao, D.F.; Huang, R.; Xiao, Y.B.; Xu, W.Q.; Liu, X.X.; Gui, Y.; Li, S.T.; Xu, J.H.; Tang, J.Z.; et al. The influence of acute ammonia stress on intestinal oxidative stress, histology, digestive enzymatic activities and PepT1 activity of grass carp (Ctenopharyngodon idella). Aquacult. Rep. 2021, 20, 100722. [CrossRef]

63. Pisoschi, A.M.; Pop, A. The role of antioxidants in the chemistry of oxidative stress: A review. Eur. J. Med. Chem. 2015, 97, 55-74. [CrossRef] [PubMed]

64. Pirinccioglu, A.G.; Gokalp, D.; Pirinccioglu, M.; Kizil, G.; Kizil, M. Malondialdehyde (MDA) and protein carbonyl (PCO) levels as biomarkers of oxidative stress in subjects with familial hypercholesterolemia. Clin. Biochem. 2010, 43, 1220-1224. [CrossRef]

65. Estevez, M. Oxidative damage to poultry: From farm to fork. Poult. Sci. 2015, 94, 1368-1378. [CrossRef] [PubMed]

66. Guo, H.; Zhou, G.; Tian, G.; Liu, Y.; Dong, N.; Li, L.; Zhang, S.; Chai, H.; Chen, Y.; Yang, Y. Changes in Rumen Microbiota Affect Metabolites, Immune Responses and Antioxidant Enzyme Activities of Sheep under Cold Stimulation. Animals 2021, 11, 712. [CrossRef]

67. Jiang, S.; Yang, Z.; Huang, L.; Yang, W.; Song, D.; Liu, F.; Ge, J.; Wang, Y.; Jiang, S. Effect of Illicium verum or Eucommia ulmoides leaf extracts on the anti-stress ability, and mRNA and protein expression of Nrf2 and TNF-alpha in Duroc $x$ Landrace $x$ Yorkshire and Chinese native Licha-black nursery piglets. J. Anim. Physiol. Anim. Nutr. 2020, 104, 1085-1095. [CrossRef] [PubMed]

68. Shi, A.; Li, T.; Zheng, Y.; Song, Y.; Wang, H.; Wang, N.; Dong, L.; Shi, H. Chlorogenic Acid Improves NAFLD by Regulating gut Microbiota and GLP-1. Front. Pharmacol. 2021, 12, 693048. [CrossRef]

69. Ma, L.; Wu, F.; Shao, Q.; Chen, G.; Xu, L.; Lu, F. Baicalin Alleviates Oxidative Stress and Inflammation in Diabetic Nephropathy via Nrf2 and MAPK Signaling Pathway. Drug Des. Dev. Ther. 2021, 15, 3207-3221. [CrossRef]

70. Abdel-Moneim, A.E.; Shehata, A.M.; Khidr, R.E.; Paswan, V.K.; Ibrahim, N.S.; El-Ghoul, A.A.; Aldhumri, S.A.; Gabr, S.A.; Mesalam, N.M.; Elbaz, A.M.; et al. Nutritional manipulation to combat heat stress in poultry-A comprehensive review. J. Therm. Biol. 2021, 98, 102915. [CrossRef]

71. Ko, S.K.K.; Paraso, M.G.V.; Pajas, A.; Dela Cruz, J.F. Immunomodulatory responses in plectasin-supplemented broilers under tropical environmental conditions. Trop. Anim. Health Prod. 2021, 53, 253. [CrossRef]

72. Shan, C.H.; Guo, J.; Sun, X.; Li, N.; Yang, X.; Gao, Y.; Qiu, D.; Li, X.; Wang, Y.; Feng, M.; et al. Effects of fermented Chinese herbal medicines on milk performance and immune function in late-lactation cows under heat stress conditions. J. Anim. Sci. 2018, 96, 4444-4457. [CrossRef]

73. Peng, M.J.; Zhang, M.L.; Wang, Z.H.; Peng, S.; Yang, Q.L.; Duan, Y.H.; Li, F.N. Effects of dietary addition of Eucommia leaves for antibiotic on growth performance, blood biochemical parameters and immune organs of weaning piglets. Nat. Prod. Res. Dev. 2019, 31, 675. [CrossRef]

74. Chen, Y.; Huang, T.; Song, X.; Lanjiao, X.U.; Liu, B.; Fu, Y. Effects of Dietary Eucommia Leaves Extract on Growth Performance and Immune Function of Broilers. Chin. J. Anim. Nutr. 2015, 27, 2224-2230.

75. Yang, S.; Zhang, J.; Jiang, Y.; Xu, Y.Q.; Jin, X.; Yan, S.M.; Shi, B.L. Effects of Artemisia argyi flavonoids on growth performance and immune function in broilers challenged with lipopolysaccharide. Anim. Biosci. 2021, 34, 1169-1180. [CrossRef] [PubMed]

76. Qi, Q.E.; Peng, Q.L.; Tang, M.; Chen, D.L.; Zhang, H.H. Microbiome Analysis Investigating the Impacts of Fermented Spent Mushroom Substrates on the Composition of Microbiota in Weaned Piglets Hindgut. Front. Vet. Sci. 2020, 7, 918. [CrossRef] [PubMed]

77. Xia, Z.H.; Chen, W.B.; Shi, L.; Jiang, X.; Li, K.; Wang, Y.X.; Liu, Y.Q. The Underlying Mechanisms of Curcumin Inhibition of Hyperglycemia and Hyperlipidemia in Rats Fed a High-Fat Diet Combined With STZ Treatment. Molecules 2020, $25,271$. [CrossRef] [PubMed]

78. Zhao, Y.Y.; Lin, Y.Q.; Xu, Y.O. Functional Identification of Allograft Inflammatory Factor 1-Like Gene in Luning Chicken. Anim. Biotechnol. 2018, 29, 234-240. [CrossRef] [PubMed]

79. Nofouzi, K.; Mirzazadeh, S.; Khordadmehr, M.; Madadi, M.S.; Amininia, S.; Firouzamandi, M.; Ranjbar, V.R. The effects of heat-killed Tsukamurella inchonensis on intestinal morphology and humoral immune responses of broiler chickens. Iran J. Microbiol. 2021, 13, 81-90. [CrossRef] [PubMed]

80. Zhao, W.; Li, X.; Li, H.; Han, Z.; Wang, F.; Liu, C.; Shao, Y.; Ma, D. Fowl adenoviruse-4 infection induces strong innate immune responses in chicken. Comp. Immunol. Microbiol. Infect. Dis. 2020, 68, 101404. [CrossRef]

81. Selim, S.; Abdel-Megeid, N.S.; Abou-Elnaga, M.K.; Mahmoud, S.F. Early Nutrition with Different Diets Composition versus Fasting on Immunity-Related Gene Expression and Histomorphology of Digestive and Lymphoid Organs of Layer-Type Chicks. Animals 2021, 11, 1568. [CrossRef]

82. Stelma, F.; de Niet, A.; Sinnige, M.J.; van Dort, K.A.; van Gisbergen, K.P.J.M.; Verheij, J.; van Leeuwen, E.M.M.; Kootstra, N.A.; Reesink, H.W. Human intrahepatic CD69+CD8+T cells have a tissue resident memory T cell phenotype with reduced cytolytic capacity. Sci. Rep. 2017, 7, 6172. [CrossRef] 
83. Hu, R.; He, Z.; Liu, M.; Tan, J.; Zhang, H.; Hou, D.X.; He, J.; Wu, S. Dietary protocatechuic acid ameliorates inflammation and up-regulates intestinal tight junction proteins by modulating gut microbiota in LPS-challenged piglets. J. Anim. Sci. Biotechnol. 2020, 11, 92. [CrossRef] [PubMed]

84. Bourret, A.; Chauvet, N.; de Santa Barbara, P.; Faure, S. Colonic mesenchyme differentiates into smooth muscle before its colonization by vagal enteric neural crest-derived cells in the chick embryo. Cell Tissue Res. 2017, 368, 503-511. [CrossRef] [PubMed]

85. Teusan, A.; Pinzariu, A.C.; Cobzaru, R.G.; Craus, S.; Jelihovschi, I.; Crauciuc, D.V.; Crauciuc, E.G.; Pasca, S.A.; Lupusoru, R.V Toxic Effects of Magnesium Nitrate on Cardiac Muscle Tissue of Gallus Domesticus Embryos and Chicks. Rev. Chim.-Bucharest 2017, 68, 1245-1251. [CrossRef]

86. Yu, K.; Gong, J.; Huang, C.C.; Huang, H.Y.; Ye, H.H.; Wang, G.Z.; Zeng, C.S. Characterization of CCT alpha and evaluating its expression in the mud crab Scylla paramamosain when challenged by low temperatures alone and in combination with high and low salinity. Cell Stress Chaperones 2015, 20, 853-864. [CrossRef]

87. Ding, H.; Cao, A.; Li, H.; Zhao, Y.; Feng, J. Effects of Eucommia ulmoides leaf extracts on growth performance, antioxidant capacity and intestinal function in weaned piglets. J. Anim. Physiol. Anim. Nutr. 2020, 104, 1169-1177. [CrossRef] [PubMed] 